\title{
Study of Related Problems for Tourism English Translation
}

\author{
Kundan Zheng \\ Tourism College, Haikou College of Economics, Haikou, 571200, China
}

Keywords: Tourism English, Translation, Problem

\begin{abstract}
Due to historical, cultural and geographic differences between, it makes when translators in China of a city attractions, food as well as the features of transliteration, hard to avoid can appear some translation errors. Compared with other professional translation of tourism English translation has its generality, there is also a feature, during the translation of scenic spots and historical sites, the translator should play, should master the skills. Therefore, this article will be on the analysis of some existing problems in tourism translation today, and it puts forward the improvement of the corresponding measures, in order to maximum range. Degree of the development of the tourism translation industry in our country, it promotes international exchange between China and foreign countries.
\end{abstract}

\section{Introduction}

With the continuous development of our economy, our country is playing an increasingly important role in the world, the impact of also more and more big, people from all over the world with curiosity and worship came here to China, see the brilliant history and culture. When foreign tourists came to China, you will go to some well-known tourist attractions, but due to differences in geography and history and culture, want to let foreign tourists with their own understanding to experience Chinese culture seems to be difficult, in addition, some translators have not through long-term training system that is mount guard work, resulting in a series of problems appeared in the process of translation, foreign tourists in this case, unable to accurately understand the local landscape features. So, in this paper, it based on this point, start relatively should put forward some views.

\section{The connotations and characteristics of tourism translation}

\section{The connotations of tourism translation}

Some professional translators are for tourism of foreign tourists providing help on language, which is called tourist translation. Tourism translation work extremely difficult, the translator must not only be familiar with the language and culture, but also explained in simple language to the scenic spots in China [1].In addition, our country has a long history of culture, idioms, proverbs, words like foreign friends is hard to understand, therefore, the translator first to let foreign friends to grasp the cultural connotation of scenic spots to a great extent.

\section{The characteristics of tourism translation}

The doohickey of English translation is that they must have a power to understand information, the most important role in tourism English translation is able to provide the guidance of the attractions for foreign friends, to help foreign friends to understand the story behind the scenic spot, so the tourism English relative to other type of translation, more difficult. Tourism translation mainly has the following features:

\section{Different genre diversity}

China is humongous, landscape types also have the difference, give priority to in order to Hangzhou west lake scenic area; Have to HuaShan, TaiShan mountain scenic area; It has given priority to with the Sichuan Wolong forest scenic area; There are predominantly river landscape area; It gives priority to in order to mount Wudang religious scenic area; Also it has given priority to with Yan' AN red scenic spot [2].In many kinds of different scenic areas involved in the history, culture, geography and other different genres. If English translator with the way of "in the hundreds of all," 
the characteristics of the tourism translators than to have more erudite knowledge, it must have the intellectual capacity like "Google".

The changed translation style

The foreign tourists who come to tourism are of its quality and each has different understandings of the Chinese language, so for some of the Chinese language ability is higher foreign tourists, the translator of attractions content interpretation with a popular expression, not the so-called "high culture". When visitors such as some other place, the characteristic of art is to translate the local characteristics, such as came to WanYaoPa poet Li Qingzhao's former residence, to their home to Jinan on the charm of language interpretation, and came to the northeast to watch the men, for example, the translator should use the most close to the tone of the local language translation, known as the "item" [3].In other words, the translator can translate language not only extremely elegant, grade, and it will be able to comply with local characteristics of life, only in this way it can translate the language is accurate.

The accuracy of the translation

Scenic spot is a national as well as the important symbol of a place, so no matter what the style and characteristics of translation, translation of the language is "high" or "the lowbrow," for some proper nouns translation must keep accurate, prevent because of the same or similar attractions translation differences caused misunderstanding. This feature is also the inevitable requirement of translation of tourism industry in China to worldwide. That does not mean, of course, all of the translator in the translation of the same attractions, the application of language and exactly the same way, this kind of situation will cause tourists.

\section{The current problems existing in the tourism English translation}

\section{Words is not accurate translation, existing cultural differences}

The translator in translation, the primary purpose is to explain words correctly. This is because the Chinese have characteristics of similar noun meaning in different context is a significant difference, but the English do not have this feature, a word synonymous with multiple words, not only can replace, use is not clearly defined, in what capacity, therefore, the translator will be Chinese and English language with the most accurate in the form of expression is the inevitable requirement. It also suggests that the translator should not only to have a strong professional foreign language comprehension, also asked to lock a vocabulary rapidly in translation to this scenario, then set sentence translation to tourists. When do translation, inaccurate wording is a common mistake. For example, in the north characteristics snacks "Leek box", for example, it has the meaning of family complete, if it is the word to literal translation, the translation appear "Leek box", and everyone knows that "Leek" is the meaning of leeks, "box" is translated into the box, and literal translation, if translators adopt such means foreign visitors will not be able to understand the true meanings of "Leek box" [4].In the process of travel, the businessman often "high-quality goods punters" for tourists, the translator in the process of translation for foreign tourists, the explanation for the words often appear the phenomenon of inaccurate wording, if the word translation, "high-quality goods" can be translated as "Boutique", the meaning of this word can be translated out of the Boutique, can also refer to a certain store of high quality, however, it does not conform to the meaning of "high-quality goods punters," in Chinese characters, "fine" in the English words are used in different occasions with different, such as "high quality" (high quality), "boutique hotel" (boutique hotel), etc. Visible, "high-quality goods punters in translation, it is best to high-quality goods as" selected ", the selected is the best choice.

\section{The bias of grammar understanding}

Before translation of a scenic spot, the translator needs to read some words of sites where again and again, who is going to translate some of the essential language for harvesting in advance, summarize into a commentary, this kind of practice is often translation professionals to do the necessary work. In this case, in the process of translation in a scenic spot, there is no chance of a syntax error, but tourism translators for some unknown or emergent problems in solution, the possibility of error is large, such as visiting a scenery, foreign tourists will put forward his opinion on 
some scenic spots and the question, therefore, in the dialogue, the translator must pay attention to the explanation of grammar. Due to the translator to foreign tourists in a short period of time to answer the questions, so can't to think carefully every word, which requires the translator to have high ability of oral expression and long-term experience in translation, can under the condition of beforehand to visitors will be asked about the preparation of the solution to a problem.

In the process of translation, if the grammar errors, it is easy to let foreign tourists misunderstanding for the cultural meaning of some scenic spots, which affect the Chinese and foreign international development. As located in Dengfeng city of Henan province at the foot of SongShan five nipple, resounded through the international "shaolin temple", in some unknown tourist introduction in "Welcome you to shaolin temple" literal language ${ }^{[5]}$.In addition, in Suzhou "HanShan temple", for example, over 1400 years ago, HanShan temple, called "wonderful benefit Samanta-prabhasa DaYuan", after a monk named "Hanshan arrived here, from a" Hanshan temple ".But in the mouth of many translators "Hanshan Temple" was translated as "Cold Mountain Temple," if you hear such translation foreign tourists, not only fail to understand the history of the Temple, are more likely to cause misunderstanding, so, according to the correct translation is "Hanshan Temple" is more accurate. Therefore, the difficulty of translation is the translator not only to master professional knowledge of translation, and each scenic spot in China history.

\section{The reason for the tourism English translation problems}

\section{The social and management reasons}

The social factor

For this, we can see this as a problem due to objective existence, social form history is hard to change, as a new industry, tourism industry with China's economic and social development to gradually raise, therefore, the lack of professional English translation of tourism is the inevitable phenomenon. If the lack of translation experience, even if good translators also still have problems, problems such as disorderly expressed in words, errors can be found everywhere.

The management factor

At present, tourism is one of the most common problems in the translation industry, when foreign tourists have some translation is not qualified personnel, who will somehow to complain, they often do not have a breakthrough, in this case, the translator can't be urged, resulting in the levels of tourism translation industry overall decline.

\section{The own problems of the translators}

Some translators are just out of the campus, step into society, lack of practice experience, when they get the translation, this position will be somewhat lax, to oneself study, review a shorter time. In addition, the study on campus is "dead knowledge", some students can't flexible communicating with foreign tourists. Or, some translators have a certain ability and professional quality, but due to the large working years, they have formed a set of translation of their own, unable to keep up the pace, they make the translation level cannot ascend.

\section{The differences of national historical and cultural}

National cultural differences are inevitable, if there is no lived in a country, it will not be able to fully understand their behavior, living habits and expression. Therefore, cultural differences are in the process of tourism translators translation cannot ignore, is also inevitable problems.

\section{Optimization measure}

\section{Improve various standards of tourism translation}

It is well known that foreign visitors step into our country, after the first contact places are the places of interest often, such as tourist attraction, as a result, the importance of distribution in resort tourism translation it is conceivable that the level of tourism translation directly affects the foreign tourists impression of our country. Therefore, responsible for the management of this problem and resort management will be hired by especially attaches' great importance to the tourism translation is in line with the professional standard. Because the enterprise is the main tourist translation such as 
travel agency "providers", therefore, our country concerning foreign affairs management institutions to strengthen the management of the travel company, improve the system of late admission and complaints, is the rules-based personnel to hire and fire. While travel companies such as tough on the professional quality of the translator, improve employment standards, it will promote our country tourism translation level to further improve.

Tourism translation should constantly improve their professional quality and knowledge skills

Due to tourism translation is a work for foreign tourists, as a result, tourism translation workers to high standards of professional quality and knowledge skills for perfect to complete its work is very important, this is the so-called hardware standards. So, tourist attractions tourism translators must be hired by the specialized level, foreign-related institutions and other departments in our country also needs to cooperate with professional translation agencies, in order to fundamentally ensure the overall level of our country's scenic spots translation work. Which requires the tourism translation must first have a certain level of English language foundation, in addition, tourism translators even before the translation service of information search, sorting, it can even to undertake advisory to foreign friends and make sure that the translation of the language of correct and accurate. And then the translator more reading, it not only needs to understand the information such as the working area is introduced, also to learn the common sense and make the translation content more rich. For school, it is to strengthen students' practical ability to use knowledge, increase the internship opportunities, real knowledge comes from practice.

\section{Understand history}

When translators translate, they should first understand the history of the scenic spots and regional culture, the local folk customs in a comprehensible language to describe. It can say foreign tourists travel is more than just want to see the beautiful scenery in the world, more important thing is he needs to know about Chinese history, therefore, the translators need to do is not only satisfy the curiosity of tourists.

\section{Conclusion}

At present, the tourism industry is in the booming in our country, the expansion of the foreign tourism is also rapid advance, excellent translators are desperately needed to society. Therefore, grasp the present, completes the labor of duty, understand the history and culture, become a qualified interpreter, it needs the joint efforts of society and individual.

\section{References}

[1] Li Anhua. The analysis of the characteristics of tourism English and translation of route choice [J]. Journal of prose hundred (below),2014(11):167-167.

[2] Zhu Liyong. Simple comment of features and translation of tourism English. Journal of Yanan journal of vocational and technical college,2014(2):72-74.

[3] Wang Ying. Tourism English language features and translation strategies study. Science and wealth,2014(7):222-222.

[4] Cui Gaili. Tourism English language features and translation strategies study. Journal of education,2014(3):131-132.

[5] Shang Hua. Introduction of tourism English translation. High school leader (teaching and research),2013(52):59-59. 